\begin{tabular}{|l||}
\hline Encyclopedia of Entomology \\
\hline \hline Springer Science+Business Media B.V. 2008 \\
\hline \hline 10.1007/978-1-4020-6359-6_2464 \\
\hline \hline John L. Capinera \\
\hline
\end{tabular}

\title{
Timarcha latreille (Coleoptera: Chrysomelidae, Chrysomelinae)
}

\author{
Pierre Jolivet $^{2}$
}

(2) Paris, France

\section{Without Abstract}

The leaf-beetle genus Timarcha Latreille comprises about four subgenera, 125 species and 30 subspecies, spread in eastern North America and around the Mediterranean basin. They are absent from Syria, Lebanon, Israel, and Egypt, where very probably European and African species once met, but were eradicated during the Pleistocene desertification. In Libya, it survives along the coast on the western side and in Cyrenaica, but also survives on some oases, $80 \mathrm{~km}$ south. Timarcha does not reach or survive in the central Sahara (Hoggar, 2,918 m) where some Chrysolina live.

Fossil Timarcha, before the Pleistocene, are unknown, but Timarcha is a very old genus, perhaps related to the Upper Jurassic Timarchopsis, a Siberian fossil. The genus Timarcha combines plesiomorphic characters (very primitive nervous system, primitive aedeagus and tegmen, etc.) with apomorphic ones, like the welding of the elytra in tenon and mortise and a complete aptery. How long has the beetle been apterous? Probably very early, during the Cretaceous, because it is found with Meloe (Meloidae), one of the rare beetles that is apterous at the pupal stage. Aptery and a subelytral cavity are forms of protection against heat and water loss in many tenebrionids living in desert and semidesert areas. Such structures reduce transpiration, act as a thermal buffer for heat flow and allows the beetle to store the maximum amount of water possible to compensate for the loss of liquid through reflex bleeding. Lack of flight muscles and shortening and widening of metasternum are a direct consequence of aptery. Pimelia spp. (Tenebrionidae), also totally apterous, often mimic the Timarcha spp. and there seems to be a certain concordance in northern Africa between the local Timarcha and Pimelia species. It could be more Müllerian mimicry than Batesian, however, because Pimelia regurgitates liquid when disturbed.

The archaic characteristics of the adult, and morphological structures of the larvae, probably warrant for Timarcha a subfamily of its own, the Timarchinae, situated between primitive ones (Aulacoscelinae, Sagrinae) and more evolved ones (Chrysomelinae). That status has already been proposed by various authors, but many others remain hesitant and prefer the status of tribe (Timarchini) at the beginning of the Chrysomelinae. Timarchini would be a monogeneric tribe with four subgenera. All other genera formerly included among the Timarchini are now listed among the Entomoscelina, a subtribe. No other Chrysomelinae has a ring piece around the aedeagus, divided at its base, with a ciliated cap-piece on the top. Several rare chrysomeline genera show a ring piece (tegmen) devoid of any cap piece on the top. Normally 
Chrysomelinae genera and species have a v or Y-shaped tegmen, a more evolved form of aedeagus. Farrell's molecular analysis of the Chrysomelinae unfortunately missed Timarcha, a key genus.

The genus Timarcha probably originated in the steppes of Central Asia, from where it has been eliminated by the Pleistocene glaciations. It adapted through a complicated system of egg or adult diapause to Middle Europe and North America, including middle-sized mountains. It still does not occupy areas that were glaciated in the Pleistocene in the U.S. and Canada (except Vancouver island) and in Europe (below Scotland, the Baltic States and Denmark). Species of Timarcha can survive moderate cold, but in Normandy, for instance, one species ( $T$.

goettingensis (Linné)) becomes active in February when the sun shines. Most of the species are diurnal, but some can be crepuscular or entirely nocturnal. Timarcha punctella Marseul in Tunisia and Libya, and T. laevigata (L.) in Morocco, are active during the day when other species in the North African mountains are mostly crepuscular. Through the Middle European mountains, adults of the subgenus Metallotimarcha Motschulsky (T. metallica Laicharting, $T$. hummeli Faldeman, etc.) seem to be mostly crepuscular or nocturnal in activity. In the United States and southern Canada, adults of the subgenus Americanotimarcha Jolivet are entirely nocturnal. During the summer, they climb over Rubus plants at around 9 p.m. and start to go down around 5 a.m. to hide under the trash, fallen leaves, and near the roots of brambles. They do the same on strawberry plants. European and African Timarcha show abundant reflex bleeding (haemorrhage) around the mouth and between femur and tibia. American species, being nocturnal and in this way being protected from most of the predators, show a very discrete bleeding. Not only does Timarcha blood taste bitter, but it is toxic in its contents (anthraquinones). Also, the purely nocturnal species of Timarcha (the American species, and also some of the Metallotimarcha) do not have the elytra fused. Probably, problems of water loss are not acute during the night.

Timarcha species fed originally on Plantago species ( $P$. albicans L., P. maritima L., etc.) and this choice is maintained with most of the African and southern European species (no data are known on Asian Timarcha). This host selection behavior is absent among north European and North American species. However, the dual choice (Rubiaceae/Plantaginaceae) is still shown along the French Atlantic coast with Timarcha maritima Perris which feeds alternatively on Galium arenarium Lois and Plantago maritima L. Many Iberian or Moroccan species have adapted to the same diet, Rubiaceae/Plantaginaceae, related taxonomically and chemically, but they eventually switch to other related plant families: Veronica (Scrophulariaceae), Scabiosa (Dipsacaceae) or not related: Launaea (Asteraceae), Carrichtera, Iberis, Alyssum (Brassicaceae). Southern species (Sicily, Spain, Morocco) display such adaptations, but generally Rubiaceae (Galium, Rubia, Crucianella, Asperula, Sherardia) along with various species of Plantago form part of the diet. There are also reports of Timarcha metallica feeding on Vaccinium spp. (Ericaceae) and other Ericaceae. The difference in food plants between Old and New World stocks of Timarcha, and the big difference in chromosome formula between the two groups, indicate a long isolation, probably since the separation of the northern land masses of the Atlantic in the early Eocene period. American Timarcha feed on Ericaceae and Rosaceae.

Timarcha is a K-strategist and lays few big eggs protected by a primitive ootheca mostly made of buccal secretions. Aptery and suppression of flight muscles likely allows the female to increase its egg production. Aptery is a serious handicap in case of fragmentation of the habitat. Once Timarcha is eliminated from a habitat, repopulation is unlikely.

Timarcha is distributed in middle and southern Europe, northern Africa and western North America, and new species are described from time to time in Turkey, Italy and Corsica. However, Timarcha has completely disappeared from central Asia, and its ephemeral and 
possible existence in Teneriffe, Japan and elsewhere (Iceland) seems to be due to accidental introduction with forage not followed by survival. Timarcha has survived in some big islands (Corsica, Sardinia, Sicily, Mallorca, Minorca) and small ones (Channel Islands, Chausey archipelago, Aegades, small islands off the coast of eastern Spain, etc.), but has disappeared or has never existed in the eastern Mediterranean islands, including Cyprus and Crete. Malta remains Timarcha free, but probably lost the beetle due to intense urbanization since the Greek and Roman times. It was connected with Sicily during the Cenozoic. Stranger is the lack of Timarcha in three small Balearic islands, perhaps due to geological history. Timarcha has disappeared completely from the eastern and central USA (Fig. 77), probably during the Pleistocene, though host plants are present in the Apalachian Mountains and elsewhere. It is also difficult to understand why the Timarcha did not cross the Sahara when it was vegetated, and did not colonize the Hoggar and the East African mountains as Chrysolina did. In some ways, the original distribution of Timarcha could have been similar to that of Pimelia and Pimeliinae in the West before the desertification of the Middle East, with a wider distribution toward Mauritania and the western Sahara, plus Egypt, Sudan, eastern Mediterranean and western Asia. 

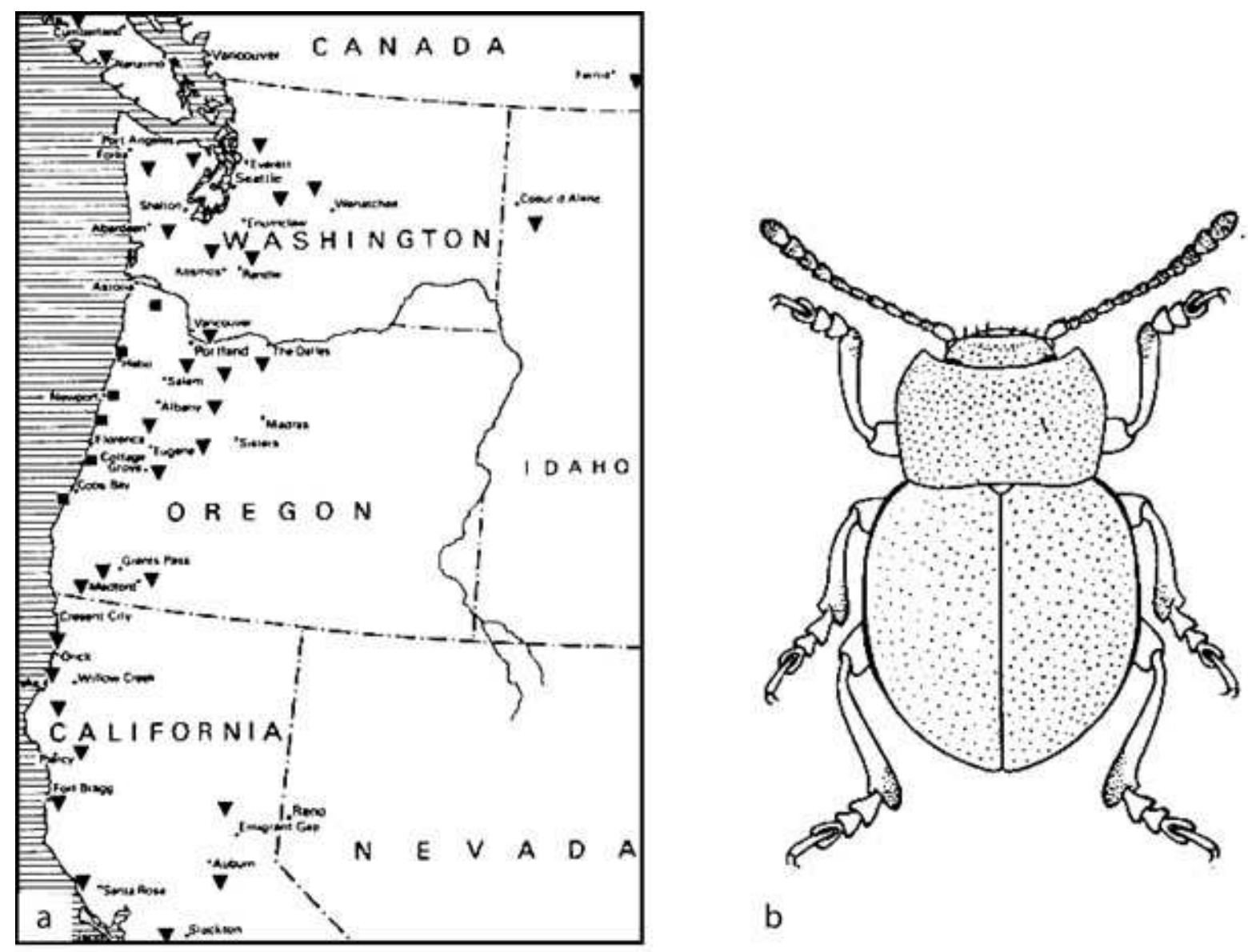

b
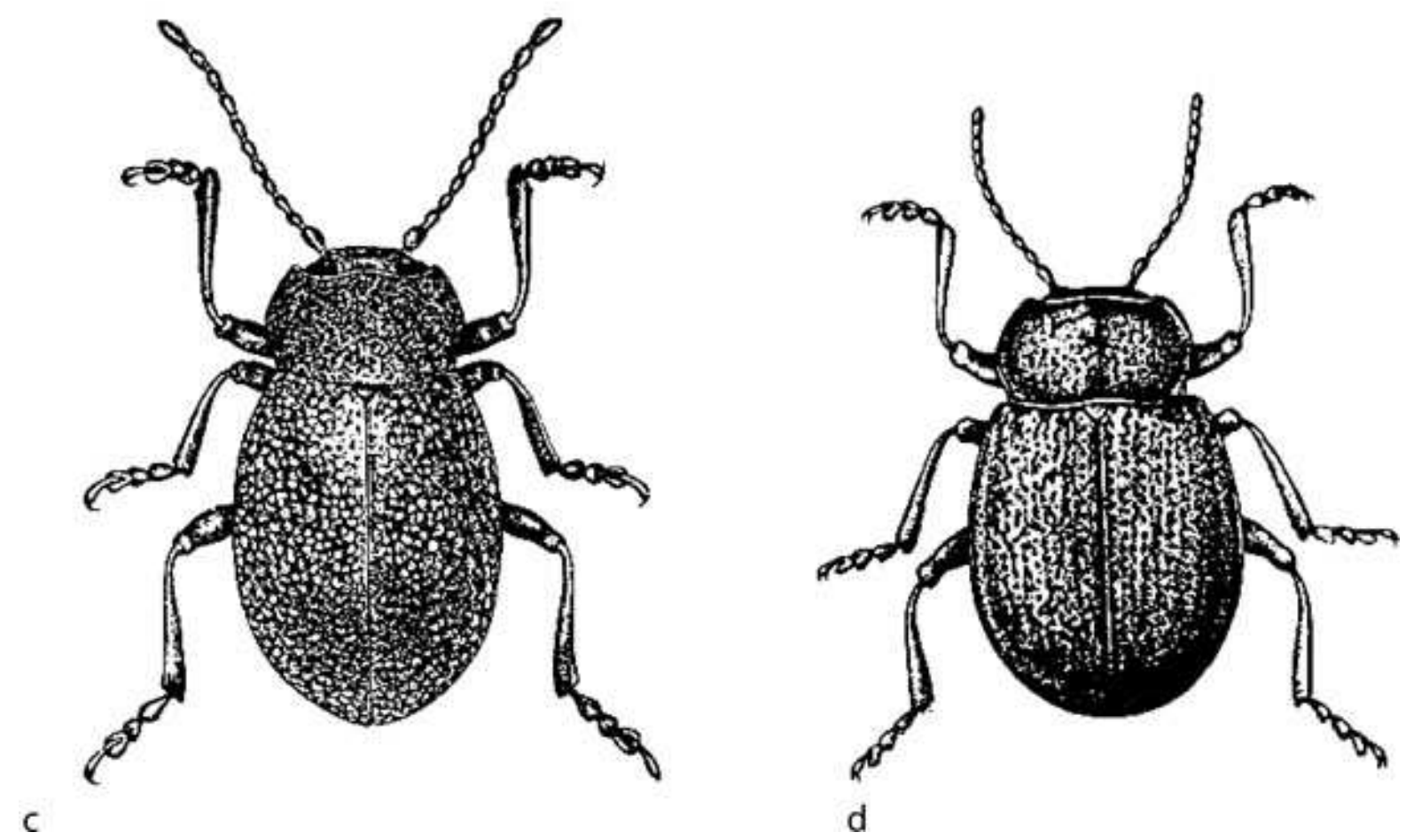

Timarcha latreille (Coleoptera: Chrysomelidae, Chrysomelinae), Figure 77 Timarcha: (a)

Distribution of the genus Timarcha in the USA and Canada. Localities in Montana are not visible on the map; (b) Timarcha (Metallotimarcha) metallica Laicharting from Belgium; (c) Timarcha 
(Americanotimarcha) intricata Haldeman, Oregon, USA; (d) Timarcha (Americanotimarcha) cerdo Stål, Oregon, USA.

Being protected by their toxic fluid (by regurgitation) and prebuccal and tibio-femoral reflex bleeding (by anthraquinones) and eventually also by a nocturnal life, Timarcha spp. have few parasites and parasitoids (Ichneumonidae and Braconidae), mites under the subelytral cavity (Canestriniidae) and microbial commensals: gregarines. Practically no predators (birds, lizards) feed on them. When resting during the cold season in the Mediterranean, adults of Timarcha often gather together under tufts of plants, showing a tendency to gregarism.

American and European species of Timarcha differ in number of chromosomes, the American species having a much greater number. The basic formula in Europe is: $2 \mathrm{n}=12$ and in America: $2 n=44$.

The black body color of Timarcha and the red blood extruded abundantly likely have an aposematic effect because of the contrast with the green background of the food plant. However, aposematism is of no use for nocturnal species.

The size of Timarcha adults varies from 5-8 $\mathrm{mm}$ (T. cerdo) to $18-23 \mathrm{~mm}$ (T. tangeriana Bechyne). Generally a size of 10-12 mm (T. goettingensis (L.)) is common.

\section{Conclusions}

The genus Timarcha remains rather enigmatic. In certain areas it seems to be evolving very quickly. Isolated valleys and mountains, acting as islands, like the Pyrenees in France and Spain, and the Atlas in Morocco, seem to be the focus of strong variation. Along the Moroccan coast and in the Pyrenees, small morphological differences, probably linked with interbreeding, sometimes show small variations in food habits. In the Pyrenees, each river, each valley seems to have a small variation.

Separation of the genus between America and the Old World has always puzzled entomo logists. Very few other cases are similar among the arthropods. Transpacific migration remains a possibility, but the genus is absent in the Far East.

Extinction is caused by urbanization, fragmentation of the habitat, use of insecticides and herbicides, general pollution and many other reasons. The survival of many species is actually in jeopardy in Europe and in the USA. Probably several species will soon be extinct, and many more are endangered.

\section{References}

Farrell BD (1998) "Inordinate fondness" explained: why are there so many beetles? Science 281:555559

PubMed ChemPort


Gomez-Zurita J, Juan C, Petitpierre E (2000) The evolutionary history of the genus Timarcha (Col Chrys.). Inferred from mitochondrial COll gene and partial 16S rDNA sequences. Mol Phylogenet Evol 14:304-317

ChemPort

Jolivet P (1994) Remarks on the biology and biogeography of Timarcha (Chrysomelidae Chrysomelinae). In: Furth DG (ed) Proceedings 3rd International Symposium on Chrysomelidae, Beijing, 1992. Backhuys, Leiden, 85-97 pp

Jolivet P (1995) A status report on the species of Timarcha (Col. Chrys.). Insecta Mundi 9:153-154

Jolivet P, Petitpierre E (1973) lantes-hôtes connues des Timarcha Latreille (Col. Chrys.). Quelques considérations sur les raisons possibles du trophisme sélectif. Bull Soc Entomol Fr 78:9-25 